\title{
Nobility and Decadence: The Vulnerabilities of Nietzsche's Strong Type
}

\author{
VINOD ACHARYA
}

\section{Introduction}

In this paper, I argue that from the point of view of Nietzsche's genealogical interpretation of history it is only when the strong type (say, the Ancient Greek culture) decays on its own terms that it is possible for a weak type (the Platonic-Christian moral culture) to come into dominance by inverting the values of the strong. I begin with Deleuze's helpful account of the onset of decadence. Through a critical examination of Deleuze's analysis of how a lapse in the "faculty of forgetting" occurs, I argue against Deleuze's account that the lapse must not be traced back to a defect in the reactive forces but rather to the very activity of the active forces. Thus my position sets right a latent inconsistency in Deleuze's work, since he too wants to establish that for Nietzsche negation (or "denial of life") is a result of creative activity. I claim that Nietzsche associates a peculiar kind of decadence with the strong type, where decadence is precisely a consequence of its abundant health. In the second half of the essay, I substantiate this claim by isolating and analyzing four typical characteristics of the strong type in order to show that these character traits not only determine the strong type as what it is, but also make it vulnerable to decadence. 


\section{The onset of decadence}

For Nietzsche, Ancient Greek culture grew in power, realizing its golden age (which Nietzsche, in his early writings, determined to be the $6^{\text {th }}$ and $5^{\text {th }}$ centuries B.C.), in which the master race dominated the weak, base, or "bad" type, as reflected in its "master morality," art, and philosophy (Beyond 153-156). Then the Socratic dialectical-moral philosophy announced the death of tragedy, an inversion of the old Greek values. Nietzsche describes Socratism as "a sign of decline, of exhaustion, of sickness, of the anarchic dissolution of the instincts" (Birth 4). Already in The Birth of Tragedy he sees Socrates as the most "questionable phenomenon in Antiquity" who dared to "negate the nature of the Greeks" (66). Nietzsche characterizes the reversal evident in the Socratic turn in the following way: "Whereas in the case of all productive people instinct is precisely the creative-affirmative force and consciousness makes critical and warning gestures, in the case of Socrates, by contrast, instinct becomes the critic and consciousness the creator-a true monstrosity per defectum!" (66). With this inversion Socrates emerges as a new type of sick individual who is "the forerunner of a completely different culture, art, and morality" in contrast to the healthy, Dionysian type (66). But how exactly is this inversion brought about? Did the Socratic weak type always exist as a distinct type lurking behind healthy Greek culture?

To answer these questions, one may turn to the later Nietzsche, who, at the end of his career, considers the problem of Socrates again. Nietzsche notes that the historic moment when Socrates came onto the scene was unique in the sense that Greek society had already been degenerating and the "old Athens was coming to an end" (Twilight 43). Socrates" arrival was timely and he understood that "all the world had need of him-his expedient, his cure, his 
personal art of self-preservation" (43). The Socratic cure was welcomed by Athenians whose instincts had become mutually antagonistic. Socrates took advantage of this situation. But this does not mean the Socratic-rational type always existed as an abstract possibility lurking somewhere in the background of the Dionysian type. Rather, the Socratic type had become. This type came into being, and took form, shape, and reality in the Greek soil itself. But it is not the same as the base, bad type that was dominated by the healthy type during the golden period of the Ancient Greeks. Rather there was a process of decadence internal to the Ancient Greek aristocracy itself, which dynamically gave birth to the rational-dialectic instinct. At a certain point in history, the rational-dialectic instinct crystallized into an autonomous type that turned against aristocratic values. Viewed this way, the mode of being Socrates expresses is not the cause but the effect or the symptom par excellence of an ongoing decaying process (39). ${ }^{1}$ In other words, it is only because the strong type undergoes decadence that the weak type is able to dominate and impose its mode of evaluation on history. The weak would not have triumphed if the strong had not degenerated on its own terms. But how does this degeneration happen? How does the new Socratic type come to be? How does the Dionysian Greek culture undergo decadence and give birth to the dialectician? ${ }^{2}$

Deleuze developed perhaps the most useful conceptual tools to date to come to terms with this central genealogical problem in Nietzsche's thought. In his 1962 book, Nietzsche and Philosophy, Deleuze introduces the notion of a "topology of reactive forces" which refers to their "change of place, their displacement" (114). For Deleuze, the topological displacement of reactive forces allows for the emergence of a new weak type that is characterized by ressentiment (114). This type - the dominance of which, for Nietzsche, effects an inversion of the earlier strong values to inaugurate a "slave morality"-is different from the previous weak 
types that were dominated by the noble type under the rule of "master morality." ${ }^{3}$ However, even though Deleuze discusses the "becoming reactive" of active forces, he considers the topology of reactive forces to be more primary. He suggests that the "becoming reactive" of active forces is a consequence of the topological displacement of reactive forces. For him, the topological displacement of reactive forces results in the "separat[ion] of active force from what it can do," which in turn leads to the becoming reactive of active forces (64). And Deleuze traces back the topological displacement of reactive forces itself to a struggle in the reactive system. I will argue that this interpretation runs contrary to Deleuze's overall reading of active and reactive forces, and also to his thesis that for Nietzsche negation and denial are consequences of activity. I will maintain that the topology of reactive forces presupposes a prior displacement of active forces. For example, with respect to Ancient Greek culture we could say that the emergence of an independent, weak, Socratic type presupposes a topological displacement of the Greek noble type.

But what does topological displacement of a type really mean? What does it involve? To explain this, let us briefly consider Deleuze's text on Nietzsche. We begin by noting that Deleuze makes an important terminological distinction between "forces" and "wills" to explain the process of topological transformation while at the same time allowing for the fact that there are two types of wills. Deleuze uses this strategy to discuss the "becoming reactive" of the active forces (Deleuze 63-72). With the decadence of the strong type, the strong will does not become the weak will, although the strong will does decay. There remain two types of will, and neither type is reduced to the other. Topological displacement refers to active forces, not wills, becoming reactive. $^{4}$ 
The starting point of our discussion is the Nietzschean concept of "body" as a tremendous multiplicity with a plurality of dominating and dominated forces in continuous mutual struggle. The body is a political structure of organized power in which the "higher type [is] possible only through the subjugation of the lower, so that it becomes a function" (Will to Power 349). The relative unity of a body is secured through this subjugation, which involves assimilation, appropriation, overpowering, forming, re-shaping, rumination, digestion, nutrition, and elimination as various forms of interpretation. Thus, the body is a "great reason, a manifold with one sense, a war and a peace, a herd and a herdsman" (Zarathustra 30). It reveals a hierarchy of dominated and dominating forces. With the will to power as the principle of interaction between the forces, we have a field of interconnected forces governed by the elemental affect of commanding. For Nietzsche, the will to power implies that that which wants to grow must evaluate whatever else wants to grow (Will to Power 342). Accordingly, at the level of forces, commanding and obeying, as basic forms of struggle, yield active and reactive forces. At the level of wills, these same forms of struggle yield the strong, affirmative will and the weak, denying will. Although there is a deep affinity between the two levels, we may still differentiate them as Deleuze does. Deleuze writes, "action and reaction are more like means ... of the will to power which affirms and denies" (54). He further remarks that affirmation is the "power of becoming active, becoming active personified," while negation is not simple reaction, but a "becoming reactive" (54).

What Deleuze means by this may be clarified by a simple example. If we consider the Ancient Greek culture as a particular "body," Nietzsche's term "strong” or "affirmative” would be used to refer to the culture as a whole. But the means employed by this culture to affirm existence are both the active (i.e., the "good") type of human being and the reactive (i.e., the 
"bad") type of human being. Both these types perform different functions within the culture that corresponds to a master morality that affirms existence. One may make similar distinctions with respect to a "weak," "denying," Platonic-Christian culture and its components. Analogous distinctions may be applied to other "bodies," such as an individual person, a nation, or a timeperiod in history.

Given this, we can observe that an affirming or denying will uses both action and reaction for the sake of its ends. Affirmation consists of active and reactive forces, since both kinds of forces must be in mutual struggle for the becoming of action. What differentiates an affirmative (healthy, strong) will from a negative (sick, weak) will is the type of relation that exists between active and reactive forces. I will analyze this issue below. The topological transition from the strong to the weak type of will consists of a transition from the type of relation between active and reactive forces characteristic of the strong will to the type of relation characteristic of the weak will. For Deleuze, this transition consists in active forces becoming reactive.

According to Nietzsche, the strong type is characterized by its active faculty of forgetting. He writes, "Forgetfulness is not just a vis inertiae, as superficial people believe, but is rather an active ability to suppress, positive in the strongest sense of the word" (Genealogy 38). The faculty of forgetting is a form of selective filtering that does not allow everything from the thousand-fold processes of strife and mutual struggle that goes on in the underworld of drives, affects, and serviceable organs to enter the realm of consciousness. It filters the content of this complicated process in order to maintain a relative unity, "a little peace, a little tabula rasa" at the level of consciousness, so that we can simply live through our experience without having to bother about how our variegated experiences are taken in, processed, assimilated, and digested 
(Genealogy 38). It sustains a relative stability and health, providing a unity to the bodily system. Specifically, the faculty of forgetting maintains the health of the system in three ways. First, it is responsible for a sort of quick recovery from bad experiences. It helps dispense with the traces of an experience that might potentially induce one to pass a slanderous moral judgment on life. "To be unable to take his enemies, his misfortunes and even his misdeeds seriously for long — that is the sign of strong, rounded natures" (Genealogy 23). Second, it makes room for something new, some new experiences, "above all for nobler functions and functionaries, for ruling, predicting, predetermining" (Genealogy 38). Nietzsche describes this faculty as the "doorkeeper or guardian of mental order, rest and etiquette" without which there could be no cheerfulness, hope, and pride (Genealogy 38). And thirdly, it is this faculty which makes it possible for one to be "done with" any particular experience, not just the bad ones; it enables one to "cope" with experience in general (Genealogy 38). The faculty of forgetting ensures that one is not overcome by victories, defeats, or spoils. Forgetting helps one to "move on."

This ability to move on is what makes it possible for one to be active, in that one can proactively welcome new experiences. The body in which the faculty of forgetting is damaged is a decadent one since it cannot cope with experience. Nietzsche repeats this characterization of decadence in section 233 of Will to Power where he maintains that "to be unable to have done with an experience" is the sign of decadence, and he explicitly associates this inability with the Christian type. It is not that the body in which the faculty of forgetting is impaired cannot perform any actions, but rather that the impaired body, unlike the healthy body, can perform only internalized actions. Internalized actions can be seen as a consequence of the "internalization" of instinct, the result of the instincts being unable to discharge themselves outwardly (Genealogy 61). Such actions are not "active" in the genuine sense of the word since, as Nietzsche observes, 
they are characterized by the "inability not to react to a stimulus" (Twilight 53). Decadence as inability to cope with or to be done with an experience brings into play the entire analysis of the faculty of forgetting, the body, and consciousness, and so is crucial for assessing Deleuze's account of the becoming reactive of active forces. ${ }^{5}$

How is consciousness related to the body? According to Nietzsche, consciousness is a superficial or surface phenomenon, which only passively reflects that the relative unity of the body has already been achieved. Consciousness is a symptom or a sign to be interpreted which hides rather than reveals the complex struggle of forces "beneath" it. The forces constituting the body engage in a long process of mutual struggle, in which each force imposes its own one-sided perspective on the whole. A kind of truce is reached between the different one-sided perspectives when a single will emerges as the commander which has subjugated resistances, and is now able to marshal the other forces as troops or instruments to accomplish the task it has set for itself. Nietzsche refers to this truce as "a kind of justice and contract" (Gay Science 186). Only when this contract is achieved, do "the ultimate reconciliation scenes and final accounts of the long process rise to consciousness" (Gay Science 186). Therefore, consciousness means nothing but "a certain behavior of the drives towards one another" (Gay Science 186). The greatest part of the activity of the forces remains hidden to consciousness which represents the mildest and calmest type of thought.

Now let us consider how the active and reactive forces are related to each other in the strong type. The strong type is strong because the active forces dominate the reactive forces, such that the latter obey the former. For Nietzsche, there is a "proper response" which is that of action (Genealogy 21). ${ }^{6}$ Deleuze interprets this to mean that in a healthy type it is essential that 
the reactive forces are "themselves acted" (111). Translated into Nietzsche's language of morality, this means that the noble method of evaluation begins by evaluating itself first, that is, by saying "yes" first to itself. The masters spontaneously act and declare, "We the noble, the good, the beautiful and the happy!" (Genealogy 22). This affirmative "yes" is the noble type's basic creative deed. Only derivatively do the masters define the base, the rabble as the "bad" ones. What is bad is something that is not good. Thus, the "good" sets the "bad" against itself as its own limit point, and it needs the limit to differentiate its elite nobility from the undistinguished. Re-translating back into the parlance of forces, we say that the active force provokes reaction; or action "precipitates reaction" (Deleuze 111).

Wherever a strong type (e.g., the Ancient Greek culture) dominates, the above relation between the active and reactive forces has been established and is the prevailing order. At that stage in history there is yet no ressentiment type corresponding to Platonic-Christian morality, but there is the subjugated bad type of Greek culture. The ressentiment type first emerges as a consequence of the disintegration of the strong type. The disintegration of the strong type involves precisely a disturbance or malfunctioning of the relation between the active and reactive forces, resulting in a topological displacement. As this decadence reaches a critical point on the topological scale, a weak type, typified by ressentiment, is born. According to Nietzsche, this new type is essentially characterized by the inversion or the "reversal of the evaluating glance" that characterized the strong type (Genealogy 21). In contrast to the evaluating stance of the strong, slave morality begins with a "no" as its creative deed. It says "no" to the previous ideals of the master, thereby branding them "evil," and only derivatively does it say "yes" to itself as "good," in opposition to the evil. Hence slave morality depends on there being "an opposing, external world ... external stimuli in order to act at all" (Genealogy 21-22). Unlike the strong 
type, for which true reaction is action, the weak type is such that "its action is basically a reaction" (Genealogy 22). Accordingly, the weak person of ressentiment is "neither upright nor naïve, nor honest and straight with himself ... his mind loves dark corners, secret paths and backdoors" (Genealogy 23). Everything appeals to him as "his world, his security, his comfort" (Genealogy 23). He does not know how to actively forget, but waits for an opportunity to exploit the other, "temporarily humbling and abasing himself" (Genealogy 23). He is inevitably cleverer than the noble person, and his cleverness is his "condition of existence of the first rank" (Genealogy 23). Accordingly, Nietzsche draws a fundamental distinction between the two types: while the strong type is dominated by the creative instinct, the weak type is governed by the instinct of self-preservation (Genealogy 29).

We should note, as Deleuze does, that there are two kinds of reactive devices in the body: one corresponding to the unconscious level, and the other to the surface level of consciousness (Deleuze 112-113). For Nietzsche, the reactive unconscious refers to the battleground in which the various forces fight for supremacy; it constitutes the "greatest part of our mind's activity" which is unfelt by the conscious body for the most part (Gay Science 186). Nietzsche describes the greatest part of mind's activity as "spiritual ingestion," invoking a digestive metaphor (Genealogy 38). It involves endless rumination (something not reducible to indigestion), since this unconscious apparatus is a passive faculty which cannot get rid of or cope with an impression once it has made its impact. It is the permanent site where "our underworld of serviceable organs work with and against each other" (Genealogy 38). It resembles the faculty of "memory," of lasting imprints (Genealogy 39). Hence Deleuze defines the reactive unconscious 
as the "digestive, vegetative and ruminative system," which is characterized by "mnemonic traces, by lasting imprints" (112).

The unconscious reactive device is indispensable for the healthy body. It is true that this device holds on to impressions and experiences and never completely digests them. But this is where the active faculty of forgetting plays a vital part. As a doorkeeper and a guardian, the faculty of forgetting actively suppresses the underworld of ruminative, thousand-fold struggles precisely in order to ensure that most of what takes places in the unconscious background does not get up to the surface level of consciousness. It suppresses the background so that consciousness - the second of the two kinds of reactive devices in the body-reflects the achieved relative unity of the body. In this sense, in a healthy body there is a unity established by a dominating active force, which transforms the other forces to be its own function. A properly functioning active faculty of forgetting symbolizes the unity of the body. It acts upon the reactive apparatuses, and when the action is successful it is reflected as a unity at the reactive level of consciousness. The active faculty of forgetting and the two systems of reactive apparatusspiritual ingestion and consciousness - thus work together in maintaining the health and strength of the body.

Functionally speaking, active forgetting makes it possible for the body's unity to be reflected at the surface of consciousness by keeping the unconscious mnemonic traces in the dark. The faculty of forgetting must be seen as the active apparatus that bridges the two reactive devices, precisely by holding them apart. Suppressing the unconscious impressions not only enables consciousness to reflect the healthy unity of the body, but it also makes it possible for a kind of freshness to be maintained at the level of consciousness so that it is able to welcome new experiences. If consciousness is fresh, present excitation is not confused with uncountable and 
conflicting mnemonic traces. Thus it is the active faculty of forgetting that acts the reactive forces-i.e., that enables conscious excitation and the healthy performance of action by the marshalling of available tools (Deleuze 113).

What happens during the process of decadence? Deleuze's answer is that the reactive forces "cease[] to be acted" because of which there is a change in place, a displacement, of these forces (114). In other words, when the reactive forces cease to be acted, unconscious mnemonic impressions invade consciousness. The mnemonic traces take the place of present excitation, both indicating the onset of decadence, and constituting a disturbance in the relation between the active and reactive forces. Nietzsche writes, "The person in whom this apparatus of suppression [the active faculty of forgetting] is damaged, so that it stops working, can be compared (and not just compared) to a dyspeptic; he cannot 'cope' with anything" (Genealogy 38-39). It is only through damage to the faculty of forgetting that the traces of memory infiltrate consciousness. A human being who suffers from this is caught up in the spirit of revenge, which is "the will's illwill toward time and its 'It was"' (Zarathustra 121).

But how does this displacement of reactive forces come about? Where do we locate the functional error - in the reactive devices or in the active faculty of forgetting? Or perhaps in both? Deleuze interprets Nietzsche's statements to mean that there must be "a lapse in the faculty of forgetting" for the mnemonic traces to invade consciousness (114). He writes that when the mnemonic traces take the place of excitation, it results in "reaction itself tak[ing] the place of action, reaction prevail[ing] over action" (114). However, he makes a perplexing argument when he traces back the faulty operation of the faculty of forgetting to the effect of a prior decay in one of the reactive apparatus. Specifically, Deleuze argues that for the faculty of forgetting to renew 
consciousness and keep it fresh for new experiences, "it constantly has to borrow the energy" from the conscious device itself, and then make this energy its own to give it back to consciousness (113). The decay in the faculty of forgetting, Deleuze maintains, results from the fact that it "no longer finds in one kind of reactive forces the energy necessary to repress the other kind and to renew consciousness" (114). The reactive forces get the better of active forces and dominate them, but not by becoming superior forces. Deleuze insists that "Everything takes place between reactive forces," and that there is a "strange subterranean struggle which takes place entirely inside the reactive apparatus" (114). Hence the lapse in the faculty of forgettingwhich results in the topological displacement of reactive forces (i.e., the invasion of mnemonic impressions into consciousness), which in turn results in the becoming reactive of active forces - is itself traced back to a struggle that belongs entirely to the reactive apparatus.

It is difficult to follow this segment of Deleuze's argument, for if the active faculty of forgetting is indeed dependent upon the reactive consciousness to furnish it with the required "energy," it is difficult to conceptualize forgetting as an "active" faculty or consciousness as a "reactive" faculty. If it is up to the faculty of forgetting to act its reactions by holding the two systems of reactions apart how can reactive consciousness in the end emerge as the unit which is responsible for supplying the requisite energy to the faculty of forgetting? Is not consciousness a passive device? Moreover, I do not believe that Nietzsche himself indicates anything that directly supports Deleuze's thesis. ${ }^{7}$

Deleuze's argument is puzzling given his own insistence that the negative "is a result of activity"-it is "a product of existence" (9). He insists on this to establish his anti-Hegelian thesis that the negative "is not present in the essence as that from which force draws its activity" (9). In the Hegelian dialectic, although activity could be conceived of as primary, the force which 
makes itself obeyed does so only by denying that which it is not. Such a conception of activity implies a metaphysics of pure act or pure thinking, but it thrives essentially on the denial of the other. In contrast, Deleuze argues that for Nietzsche the force which commands and says "yes" first to itself "affirms its own difference and enjoys this difference" (9). The negative is a result of activity, not an essential determination of it. The will to power is not a purely positive essence, but the denying will is possible only due to the active principle of the will to power as will to growth. However, Deleuze's proposal that "everything takes places between reactive forces" and that the active faculty depends on the reactive apparatus for its energy seems to suggest that the negative (as decadence) does not result from activity. Instead, it results from a prior negative activity "that takes place entirely inside the reactive apparatus." Hence it appears that Deleuze's account of the origin of decadence is inconsistent with his thesis about the origin of the negative. His account places decadence purely on the side of reactive forces.

To set right this inconsistency, I argue that the origin of the disturbance to the active faculty of forgetting lies in the active apparatus itself. This would indeed establish Nietzsche as the anti-Hegelian philosopher par excellence as Deleuze wanted to do. Decadence does not have its source in a prior reactive process. The becoming reactive of the active forces is a possibility that belongs to the active forces, to their very activity. Hence there is an irreducible ambiguity in the decadence of the strong type. The active forces are not only "delegated by activity to work with reactive forces" and their activity is not merely "functional," as Deleuze maintains (113). The active forces have the freedom to exceed this functionality precisely as an affirmation of the strength of the body. And it is this excessive quality that makes the active apparatus vulnerable 
to decadence. As I will show in the next section, the tendency to exceed mere functionality is grounded in the very fundamental instinct of the strong type, which is its creative instinct.

It still holds true that the emergence of a new weak type - the sick type of ressentimentis connected to the topological displacement of reactive forces. And to this extent, my argument is similar to Deleuze's. However, I differ from Deleuze in that I locate the source of the topology of reactive forces in a prior topological displacement of active forces, which is a result of their very activity. Moreover, even if we were to assume with Deleuze that it is the reactive apparatus that is ultimately responsible for decadence, he has no account of why there is a lapse of forgetting or how this lapse of forgetting itself happens (or, in other words, why or how the reactive conscious apparatus cannot provide the necessary energy to the faculty of forgetting). Deleuze does not indicate how those decisive moments in history - that trigger the topological process of transition of active forces - are themselves brought about. At crucial points in his text, Deleuze just passes over this issue: "Let us suppose that there is a lapse in the faculty of forgetting" (114), or "let us suppose that, with the help of favorable external or internal circumstances, reactive forces get the better of and neutralize active force" (56). But what are these "favorable external or internal circumstances"? I suggest that Deleuze does not really take up this issue precisely because he locates the cause of the faulty operation of the active faculty in the reactive apparatus. With such an account, if one tries to indicate what the favorable circumstances are one is able to come up with only a still prior reason which is located in another reactive feature of the body. To avoid this regress, we must locate the circumstances conducive to the lapse in forgetting in the activity of the forces themselves. In doing so, we would show how the nature of activity itself leads, at a certain point, to a condition which makes the strong vulnerable to a lapse in the forgetting function. 
In what follows, relying on Nietzsche's later texts (from The Gay Science onward), I isolate four typical characteristics of the strong type that not only make the strong type what it is, but also make it vulnerable to decadence. I refer to the four distinctive traits as the "virtues" of the strong (the final trait, "corruption," is more of a consequence of possessing virtues such as the other three). With respect to each of these four characteristics, I show that there is the real possibility of a conflict between the strong type's "will to create" and its "will to selfpreservation." This conflict signifies a point of vulnerability to decadence insofar as it leads to a lapse in forgetting. The active force of forgetting may exceed itself. If too much is forgotten, the drive to create will exceed the limits of self-preservation, imperiling creativity itself. Such risk is always present, but not always excessive, in the strong type. When it becomes excessive the domination of the strong type declines. In the four sketches that follow I suggest that Nietzsche understood the strong type as vulnerable to such decline. Thus the sketches begin to make the case for the thesis that the decline of the strong type originates in excessive active force.

\section{The "weak" sides of the strong}

\section{(a) Solitude}

The strong type is essentially creative, and the strong person creates her own values. Strong morality is based on an awareness of the distance between the strong and the weak. This situation is in contrast to that of weak morality, especially the slave morality of ressentiment. Pity for others' suffering, equality, mediocrity, and justice for all are some of the ideals which weak morality preaches, even though this preaching betrays the underlying quality of the will to power that takes pleasure in conspiring against and defeating the strong. However, there is 
strength in this morality of numbers: the strength of self-preservation. In its dealings, the weak type never loses sight of its advantages, and the "thought of purpose and advantage is even stronger than its strongest drives" (Gay Science 31). It is this very conserving principle that is not dominant in the strong, which "succumb[s] to its drives" (31). The greatness of the strong type lies in its "being different, in incommunicability, in distance of rank" (Will to Power 468). The noble soul is typically reluctant to admit of equals to itself. It takes pride in the duties it sees as its destiny, and is neither eager to share these duties with other people, nor perform them for the sake of others. But it is exactly this quality of the strong which constitutes its solitude and isolation. Nietzsche describes "solitude" as the strong person's "virtue" (Beyond 171). And as a virtue, it is something that is possessed in "common with no one else" (Zarathustra 31). He associates such lofty notions as the destiny of humankind with the fate and responsibility of the stronger, higher nature. This heavy responsibility creates a solitude that is inaccessible to praise or blame, and a sense of justice that is beyond appeal. The strong person is rare and must live alone, away from the "market-place," the petty, and the wretched (Zarathustra 45-47). Only individuals able to endure and love themselves sufficiently, uninterested in comfort, are able to breathe the icy air of solitude.

There are dangers and challenges inherent in the solitude of the strong type that point to a conflict between its essential will to create and its will to self-preservation. This conflict reflects the greatest challenge for the strong type, which is to exercise its creative instinct while, at the same time, preserving or maintaining itself. There is a very thin margin of error at the height of this conflict. The strong type often risks self-preservation in order to create and grow (Gay Science 31$){ }^{8}$ We must note that the weak type does not have to contend with the conflict between creation and self-preservation because it is dominated by the will to self-preservation. 
From this point of view, the weak has an advantage over the strong. Hence Nietzsche suggests that the "spoiling" or "rotting" (Verderbniss, author's trans.) and the "destruction" (Zugrundegehen) of the strong type are the rule rather than the exception (Beyond 164). Before examining how solitude may lead to decadence understood as a kind of spoiling we will briefly consider how solitude may result in the destruction or perishing of the noble type.

The person who carries out tasks in solitude risks being misunderstood. There is also the tendency for noble souls to misunderstand one another because of the unique meanings of each of their tasks. At times they remain hidden and even misunderstand themselves (Will to Power 465-466). They "suffer too deeply from the smallest wounds" (Zarathustra 46). ${ }^{9}$ The strong soul shivers in the "frost of solitude" and there is a danger it "might become insolent, scornful and an annihilator," and that it might lose its "highest hopes" (39). Living alone also means a noble person is prone to accidents and rarely propagates. Because of the diversity of the noble type's conditions of life the "likelihood that it will get into an accident and be destroyed [zu Grunde geht] is truly enormous" (Beyond 168).

Most importantly, there is a pride associated with solitude which demands that the solitary keep his or her distance from the common and the wretched. ${ }^{10}$ The solitary one preserves and conserves herself by avoiding mingling with the common. ${ }^{11}$ However, because of its proud solitude and reticence, the noble soul can "misjudge[ ] the sphere [of the base] it despises" (Genealogy 22). For instance, one cause of misjudgment is the incorrect self-estimation by means of which alone the strong may continue to endure the weak type, albeit from a certain distance (Zarathustra 158-161). But this just means that the strong misjudges the worth of, and is gentle toward, the weak, even though the latter may not deserve it. The weak repays the strong 
type's generosity by taking advantage of the erroneous self-estimation in a cruel manner; it makes the noble type pay dearly for the mistake in its judgment by subjecting it to slander, suspicion, and conspiracy. It punishes the strong for its virtues, and thus subjects it to its "poisonous injustice," which may in the end be responsible for the strong type's "undoing" (Zarathustra 46-47). ${ }^{12}$ To make matters worse, the strong natures then take "revenge" on themselves for misjudging themselves and for being gentle towards the ignoble many (158-161).

This series of events culminates in the spoiling or rotting of the strong and has at its origin the pride associated with solitude. The misjudgment of the common, which results from proud reticence, must not be seen merely as a "fault" of the strong, but more crucially as a consequence of its overabundance of strength. This overabundance compels the noble type to maintain its distance from the common, as is essential to exercise its creativity, but it also may lead to various misjudgments and deeply reactive repercussions, signaling the beginning of the strong type's degeneration. Due to an excess of activity, the strong type forgets its place, missteps, and misjudges the place and worth of the weak. Thus solitude reveals one possible way in which there could be a lapse in the forgetting function, making the strong type vulnerable to decadence.

\section{(b) The Bestowing Virtue}

Out of solitude comes the great need to bestow. Zarathustra expresses this thought at the beginning of the second part of Thus Spoke Zarathustra, when he finds himself drawn toward the very human beings from whom he had previously withdrawn: "Indeed a lake is within me, solitary and self-contained; but the river of my love draws it off—down to the sea!" (72). Unlike the theoretician or hermit whose abstractions remove him from the world, the joyful wisdom of the convalescent draws him toward the very world which he must now, with necessity, create 
and shape from his will. "And what you have called world, that shall be created only by you: your reason, your image, your will, your love it shall become!" (74). But what kind of necessity is it that draws the noble person to the world? It is the necessity born out of "love." For Zarathustra, love has the quality of superabundance or excess; love, essentially has the quality of "flowing-over" to the other. Zarathustra says, "My impatient love overflows in torrents, downwards, toward rising and setting" (72). We must understand bestowing as the highest virtue, involving the surging of heart with overflowing love and the compulsion to give. The one who bestows has the thirst to pile up all riches in his soul, and therefore, like a star, he compels everything towards him, not in order to devour them, but rather so that these things flow back out of his "wells as gifts of [his] love" ( 65). There is a happiness associated with the power that wants to overflow, that is conscious "of a wealth that wants to make gifts and give away" (Beyond 154).

But what does the bestowing virtue give? And what effect does this virtue have on the individual who bestows? Nietzsche's answer is that only through bestowing does one create values. Bestowing is the highest virtue of the strong creator-soul. The necessity with which the giver gives pertains to the necessity of the one who wills with one will (Zarathustra 65-66). And when the strong individual wills in this way, she is liberated (73-75). The lover experiences freedom. And out of this experience, she attempts to create the world in her own image, by tempting and seducing the world through the virtuous strength of her will. Bestowing and creating are thus the great redeemer of the strong and healthy person who had suffered under the "spirit of gravity," carrying the responsibility of the world on her shoulders. Bestowing redeems by making the creator "lighter," and thus may be seen to perform an active "forgetting" function 
(73-75). Nietzsche often uses the metaphor of "pregnancy" to describe the plight and redemption of the creator. The "wild wisdom" of the creator becomes "pregnant on lonely mountains," and she reaches a point where her wisdom wants to overflow (73). The solitary's "great love of oneself" is the true sign of her pregnancy (139). She has suffered enough in bearing the questionable burden of humankind, and in being assigned the task of its future course. As the creator becomes ripe with her pregnancy, she begins her "going-under" (untergehen) and going beyond herself. The burden the creator bears can be lightened only if she finds her "children," that is, the values she can call her own. She realizes that she cannot discover her children and her values already present in the world. Rather she must invent them first. She gives birth to her values, and through this creative deed, she redeems and unburdens herself. In thus overcoming herself, she determines the course of future humanity and redeems the past (176-177).

But these very virtues of love and bestowal can also make the strong type vulnerable to weakness. The strong type tends to be naïve precisely because of its bestowing power. Because the compulsion to bestow is blind, the strong soul can often suffer "attacks of [ ] love" and it can be indiscriminate about the kind of person towards which it extends its giving hand (Zarathustra 56). For instance, the strong person may irrationally waste gifts on the common people, who only hate and vilify the former for inventing virtues. This irrationality and blindness imply an inability to see the "commonplace people as what they are" (Gay Science 31). The exceptional natures "do not themselves feel like exceptions" and therefore they fail to "understand the common natures and arrive at a proper estimate of the rule" (32). As a result, the higher natures are sometimes not able to keep that essential "distance" from such people, and thus may not be able to preserve themselves and their energies for worthier tasks. Nietzsche calls this the "eternal injustice of the noble" (32). The misjudgment of the base type and the inability to maintain the 
essential distance from them may be interpreted as involving excessive forgetting on the part of the strong natures. Bestowing as forgetting is required to relieve the noble type of the questionable burden of humankind. However, loving and bestowing indiscriminately, as extreme manifestations of the creative drive, result in the active force of forgetting exceeding itself, because of which the strong fails to keep its distance from the weak. Paradoxically, this excessive forgetting appears precisely as the failure to forget, as the strong soul, which naively loves even those unworthy of its love, ends up "carr[ying] on its shoulders too much that is alien" (Zarathustra 167). Thus, "love is the danger of the loneliest, love of anything if only it is alive!" (133). We see here a necessary conflict between the will to create, which at times compels it to bestow its love upon others indiscriminately, and the will to preserve oneself which demands that the strong type use its bestowing virtue prudently.

However, the strong type pays a huge price for exceeding its creative drive beyond the limits of self-preservation. As it carries too much burden on its shoulders, at its more susceptible moments the strong soul may expect something (perhaps, a kind of recognition or mutual understanding) from the weak upon whom she bestows. Such expectation may lead to a chain of repercussions that ultimately leads to the disintegration of the noble type. In bestowing gifts upon humankind the strong natures can naively assume that their "own passion [is] something that is present in everyone" (Gay Science 31). They expect and hope that there is someone who "approaches them with as much as a thousandth part of their suffering and passion" (Will to Power 509). When this hope is upset, the strong person thinks to himself, "They take from me: but do I yet touch their souls?" (Zarathustra 91). However, he soon realizes that there is an infinite chasm between giving and taking, which cannot be bridged, and that he cannot know 
about the happiness of those who take. This discovery might lead to frustration due to which there is a danger that the noble natures lose "their sense of shame," and their "hands and heart[s] [may get] calloused from sheer distributing" (92). A spite may grow up from the depth of solitude, which desires to "cause pain to those [they] illumine" and to "rob those upon whom [they] have bestowed" (92). Thus the frustrated strong type hungers after wickedness and revenge. This is another manner in which spoiling or rotting may arise from excess of strength. Zarathustra says: "Withdrawing the hand when another hand reaches out for it; hesitating like the waterfall, which hesitates even in plunging — thus do I hunger after wickedness" (92). Hence the strong type may feel that bestowing itself is a curse. Just like a star, which can neither expect the planets and other bodies revolving around it to illuminate, nor other stars to do the same for its sake, the strong type is left to contend with the wretchedness of its bestowing power. As a consequence, there is a danger that the strong individual's "joy in bestowing die[s] away through bestowing," and the bestowing "virtue gr[ows] weary of itself in its overflow!" (92). The greatest task for the bestowing nature, therefore, is to "preserve [its] modesty as a bestower" (71). And this task is incredibly difficult to achieve consistently. Thus the bestowing virtue, which essentially characterizes the activity of the strong type, also makes this type vulnerable to frustration, weariness, disillusionment, and to decadence.

\section{(c) Need for challenges}

In accordance with its will to demonstrate over-abundance of power, the prodigal will desires challenges. The greater the challenge, the grander is the platform on which such a will can put its power and magnanimity to the test. This is why the strong person has a "certain need to have enemies" (Beyond 155). A strong individual honors and respects her enemies, since the great enemy pushes her to examine the extent and limit of her own strength and courage. She 
seeks challenges to overcome. We must acknowledge that the need to have challenges is not just an empty show of egoism. Rather, it belongs essentially to the creative impulse of the noble type. “That one stakes one's life, one's health, one's honor, is the consequence of high spirits and an overflowing prodigal will" (Will to Power 499). The strong type, who commands, has a deep necessity to be adventurous and experimental. But this life-affirming necessity also makes the type vulnerable to dangers and destructions, a vulnerability about which the weak knows little. Commanding is much more difficult than obeying, and often the one who commands puts his whole life at risk. This is so since the "commander bears the burden of all who obey, and this burden can easily crush him" (Zarathustra 99). Just as the smaller person yields and makes way for the greater, such that the latter exercises power over the former, "so does even the greatest yield, and risks for the sake of power-life itself" (99). In this dice-playing with life and death in the balance the strong type becomes its own sacrificial victim. For the sake of power, life is sacrificed, since life is something "which must always overcome itself" (99). In other words, since the principle of life is will to power, the preservation of life in the strong type takes a backseat to its creative and life-affirming impulse: "the tremendous squandering of all defensive energies [ ] is a presupposition of every creative deed ... Our small defensive capacities are thus, as it were, suspended; no energy is left for them" (Ecce Homo 304).

However, risking one's life is not the only possible consequence of this conflict between self-preservation and creation. The excessive activity of the strong could lead to this type becoming reactive if it results in damage to the faculty of forgetting. The will to power of the creative type always looks for new dangers and unexplored horizons. Nietzsche notes that "a preference for questionable and terrifying things is a symptom of strength" (Will to Power 450). 
A dormant power becomes a sort of vice and a symptom of weakness. The healthy, creative power needs to bestow, grow, explore and widen its sphere of influence. However, undertaking this challenge means to be "destructive also towards oneself" (499). This can happen, perhaps, by desiring dangerous challenges for which one's prowess is inadequate, or by desiring enemies one would have been prudent to avoid. These dangerous desires are the result of the "lust to rule," because of which the higher type "compels itself down to the low" (Zarathustra 163). Such desires are indications of excessive forgetting where the strong forgets the "pathos of distance" essential to its nature as the creator of values. The pathos of distance, as Nietzsche argues, is what allows the noble type to "maintain[ ] an overview and keep looking down on subservient types and tools" (Beyond 151). Therefore, the forgetting of this pathos because of which the noble soul compels itself down to the lower type imperils creativity. It may be the case that the strong is interested in the weak since it is curious about the degree of its own strength and courage (Will to Power 499). It is not content with a self-satisfied life that is happy in the safety of its own convictions and victories. It seeks new spoils and it sacrifices itself for the sake of the future. It has always wanted to glimpse the limits of its strength by discerning "how much of the 'truth' [it] could withstand," and how much it could push itself to the limits without destroying itself (Beyond 37).

Hence Nietzsche calls "virtue" in the form of "truthfulness," the "noble and dangerous luxury" (Will to Power 498). The weak represent the perilous limit, because of which they appear "malicious" and "interesting" (460). The strong person "takes an interest in the people, the weak, the poor, the poetry of the petty, etc.," since this interest brings with it new challenges, which opens up new avenues and paths untraveled heretofore (494). Comprehending the interesting weak types might just represent the ultimate challenge for the will to create, even 
though, or precisely because, this challenge is fraught with the greatest dangers. The danger here is precisely that the noble type's active forgetting forgets too much, that is, it forgets the necessity to preserve a certain distance from the weak. We may say that a certain recklessness belongs to the creative impulse of the strong as a kind of sickness, even though this sickness is a sign of excessive health (522). Thus the reckless search for new spoils reveals one way in which the strong type could become vulnerable to decadence.

\section{(d) Corruption}

Corruption of instincts is another factor in the disintegration of the strong. Corruption is "an expression of the fact that anarchy threatens inside the instincts and that the foundation of affects, which we call 'life', has been shaken" (Beyond 152). Corruption might mean that an aristocratic race "throws away its privileges with a sublime disgust and sacrifices itself to an excess of its moral feeling" (152). For Nietzsche, one of the essential traits of the noble type is a certain awareness of its wealth, which this type does not want to preserve but wants to expend, as a sign of its strength. When it helps the unfortunate, it is not out of pity but from an impulse, which is a result of overabundant power (153-156). But how does the instinct for giving and bestowing turn into a kind of squandering, even at the expense of the disintegration of the self? To answer this, we must note that for the strong person to be creative she must harbor within herself an excessive tension of contradictory forces in mutual strife. As Zarathustra says, "One

must have chaos within, in order to give birth to a dancing star" (Zarathustra 15). Nietzsche often uses the metaphor of "the bow with the great tension" to describe the great human (Will to Power 507). The strong person possesses great virtues and also their opposites which form a 
creative tension. But this blessing of having an excessive tension is also a kind of curse, which makes the strong vulnerable to corruption of instincts, and perhaps even to decadence. How?

In Thus Spoke Zarathustra, Nietzsche writes that the greatest evil to grow out of the strong ones is "the evil that grows out of the conflict among [their] virtues" (32). This conflict of virtues is the reason behind the corruption of instincts. The many virtues that the strong "body" possesses are in constant mutual struggle for dominance and for the highest place. Each virtue wants the strong person's "whole spirit" and "whole strength," such that it can announce itself as the only virtue which expresses itself in the passions of "wrath, hatred and love" (32). Hence Zarathustra declares, "if you are fortunate you will have one virtue and no more: thus you go more easily across the bridge" (32). Each virtue is jealous of other virtues. However, the struggle between virtues is not an unfortunate situation which must be avoided. Rather, this "evil" is necessary; "envy and mistrust and calumny" are necessary among the virtues since this evil essentially defines the strong type (32). But it is precisely envy and calumny between the virtues that result in the corruption of the strong type's instincts. The strong individual, who is the battlefield of virtues, may grow "weary" of the battle. Indeed, he may go to the "desert and kill[ ] himself" (32). Zarathustra warns the healthy one: "therefore shall you love your virtues-for by them will you finally perish" (33).

However, the danger here is not necessarily that the strong will finally perish as a result of the struggle between virtues. There is also the possible danger that corruption results in excessive forgetting, thus signifying vulnerability to decadence. To see this possibility, we must consider some consequences of the corruption of instincts. On the one hand, I would like to suggest that one main implication of the corruption of the instincts is the development of "pity" for the base type. Nietzsche speaks of pity as Zarathustra's ultimate "temptation" and "final sin" 
which will lead him astray and distract him from his tasks (Ecce Homo 228). ${ }^{13}$ There is a great peril that the "cry of need" of the "superior humans"-whom Nietzsche portrays in the figures of the "kings," "soothsayer," the "ugliest man," the "sorcerer," the "shadow," etc., in the final part of Thus Spoke Zarathustra — will lead the strong person away from himself such that he believes he can find refuge in the safety of "pity for the suffering" and "selfless" actions as a way of relieving himself of the great tasks assigned to him. It is almost as if the strong soul, in its vulnerable moment, wishes that it were "like" the weak. This tendency indicates excessive forgetting in the sense that the strong forgets its "distance" from the weak. ${ }^{14}$ The development of pity for the suffering signifies forgetting in a unique way. The battle between the virtues essentially defines the active nature of the strong type. But if the strong grows weary of the battle, it is not able to "suppress" or "forget" the struggle such that the traces of the struggle enter the level of consciousness, indicating the onset of corruption. The strong type ends up forgetting its distance from the weak, misjudging and developing pity for the latter, leading itself away from its tasks.

On the other hand, instead of an attempt to renounce one's tasks, there is the tendency to squander the noble privileges as a consequence of corruption. The extreme tension between virtues gives rise to a "spiritual disturbance," which in turn leads to wastefulness, adventurousness and thirst for power (Will to Power 462). Through these excesses the strong take revenge for "some inner corruption" (Beyond 165). These excesses may be shown to result in the same kind of indulgences that we saw in the previous subsection with respect to the strong type's need for challenges, and hence leading to similar instances of excessive forgetting. In 
these ways, corruption not only reveals the conflict between the strong type's creative will and its will to self-preservation, but also its vulnerability to decadence.

\section{Conclusion}

The analysis of each of the above four characteristics reveals a deep conflict between the creative and the self-preserving instincts of the strong type, in which this type submits to the former instinct at the expense of the latter. I have shown that this conflict may lead to a lapse in the faculty of forgetting, signaling the onset of decadence. The conflict between creation and self-preservation may result in the active force of forgetting exceeding itself. Too much forgetting implies that the will to create exceeds the limits of self-preservation, endangering creativity itself. With respect to the traits of solitude and the bestowing virtue, excessive creativity was shown to lead to misjudgments of the weak - as evidence of a kind of excessive forgetting-which in turn results in a series of reactive repercussions culminating in the decadence of the strong. And with respect to the need for challenges and corruption, excessive forgetting manifests directly as the inability of the strong to maintain its distance from the weak. These lapses in the faculty of forgetting result in a displacement of reactive forces, which in turn ensures that the reactive forces are not acted upon. In short, the damage to the faculty of forgetting is not due to a struggle in the reactive apparatus, as Deleuze suggests, but is a consequence of the dominant strong type's excessive activity.

The analysis provided here needs to be brought to bear on the particularities of the decadence of a strong culture like that of the Ancient Greeks. Nietzsche's early writings and lecture courses on Greek politics, art, and philosophy contain plenty of complex and nuanced reflections regarding both what constituted the glory and disintegration of that culture, and what 
led to the birth of Socratic philosophy. Working with Nietzsche's insights, a future study should explore how the characteristics peculiar to the strong type manifest themselves in different aspects of Greek culture, and how they might have come together, as it were, to actualize the decadence of that culture. The task of pursuing such a study, however, must be reserved for another occasion.

\section{Notes}

${ }^{1}$ As the leaders of the "herd," the "ascetic priests" (like Socrates) would play an important and decisive role in the re-interpretation of the old weak type and their power structures, and therefore in the inversion of values.

${ }^{2}$ It is unproductive at this juncture to say that there is a "natural inevitability" to the decadence of the noble type. Conway, for instance, writes that "declining ages inevitably succeed healthy ages; strong peoples naturally degenerate into weak peoples," and that Nietzsche views Western history in terms of a "renewable cycle of inexorable growth and decay," which is governed by a "natural" immutable law (72). Even if this natural law of history were the case it would not make the process of the decadence of the strong any less problematic and question-worthy. The decadence of the strong is one of those terrible and tragic processes, upon which Nietzsche ceaselessly meditated. The question "why did life, physiological well-constitutedness everywhere succumb?" triggers and defines the very trajectory of his genealogical thought (Will to Power 217).

${ }^{3}$ Nietzsche characterizes the notions of "master morality" and "slave morality" in section 260 of Beyond Good and Evil.

${ }^{4}$ Further, for Deleuze, "active" and "reactive" are not purely quantitative terms, but they refer to the quality of forces, where quality refers to quantitative differences (Deleuze 42-44; Nietzsche, Will to Power 304-305).

${ }^{5}$ Nietzsche provides various other definitions of decadence: for example, he writes in Will to Power that decadence is the "inability to guard against any infection" (105). Elsewhere, he claims that the anarchy of instincts is a symptom of decadence (Twilight 41), and also that the need to combat one's instincts is symptomatic of degeneration (Twilight 44).

${ }^{6}$ Nietzsche's original reads: “... die eigentliche Reaktion, die der Tat ...” 
7 Perhaps, Deleuze's argument is partly inspired by Freud's view of the relation between consciousness and the unconscious. In the passages where he presents his argument, Deleuze compares his account to that of Freud's "topical hypothesis" (112).

${ }^{8}$ See Gay Science 207-208, where Nietzsche remarks, "To wish to preserve oneself is a sign of distress, of a limitation of the truly basic life-instinct, which aims at the expansion of power and in doing so often enough risks and sacrifices self-preservation."

${ }^{9}$ We must note that this characteristic of the strong type is ambiguous because Nietzsche also often describes the weak type as suffering from small wounds (since the latter type has an inability to forget or "digest" its bad experiences).

${ }^{10}$ Here, the "common," the "wretched," the "base," the "weak," and the "sick" are not terms for the unique character of ressentiment which comes to define the dominant slave morality after the strong has been defeated. Rather, these terms refer to the weak type under the rule of the master morality. Of course, this does not mean that the two weak types do not share common features. On the contrary, they share a large number of common traits, since self-preservation is the dominant drive in both weak types.

${ }^{11}$ See Gay Science 166, where Nietzsche notes that the higher nature must take precautions to ensure that "large amounts of [its] strength are not sapped uselessly!"

${ }^{12}$ In a discarded note originally intended to be included in a passage in Ecce Homo, Nietzsche writes, "If there are any means at all for destroying men who are destinies, the instinct of poisonous flies discerns these means. For one who has greatness there is no fight with the small: hence the small become masters" (Ecce Homo 303 [footnote 3]).

${ }^{13}$ Also, see Zarathustra 210-213.

14 Nietzsche warns that "the healthy should remain separated from the sick, should even be spared the sight of the sick so that they do not confuse themselves with the sick" (Genealogy 97). The development of pity may be seen as an instance of such confusion.

\section{Works Cited}

Conway, Daniel W. Nietzsche's Dangerous Game: Philosophy in the Twilight of the Idols. Cambridge University Press, 1997.

Deleuze, Gilles. Nietzsche and Philosophy. Trans. Hugh Tomlinson. New York: Columbia University Press, 2006. 
Nietzsche, Friedrich. Beyond Good and Evil. Trans. Judith Norman. Cambridge: Cambridge University Press, 2002.

- The Birth of Tragedy. In The Birth of Tragedy and Other Writings .Trans. Ronald Speirs. Cambridge: Cambridge University Press, 1999.

—. The Case of Wagner. In Basic Writings of Nietzsche. Trans. and ed. Walter Kaufmann. New York: Modern Library, 2000.

- Ecce Homo. In On The Genealogy of Morals and Ecce Homo. Trans. and ed. Walter Kaufmann. New York: Vintage Books, 1989.

—. The Gay Science. Trans. Josefine Nauckhoff. Cambridge: Cambridge University Press, 2001.

—. On the Genealogy of Morality. Trans. Carol Diethe. Cambridge: Cambridge University Press, 1994.

- Kritische Studienausgabe. 15 vols. Ed. Giorgio Colli and Mazzino Montinari. Berlin: Walter de Gruyter, 1999.

—. Thus Spoke Zarathustra: A Book for Everyone and Nobody. Trans. and ed. Graham Parkes. New York: Oxford University Press, 2005.

- Twilight of the Idols. In Twilight of the Idols and The Anti-Christ. Trans. R.J. Hollingdale. England: Penguin Books, 2003.

- The Will to Power. Trans. Walter Kaufmann and R.J. Hollingdale. New York: Vintage Books, 1968. 